\title{
Removal of Tracheobronchial Foreign Bodies Using Flexible Bronchoscopy - A Retrospective Study.
}

\author{
Indrajit Rana ${ }^{1}$, Jugindra Sorokhaibam ${ }^{2}$ \\ ${ }^{I}$ (DNB General Surgery Resident, Shija Hospitals \& Research Institute, Imphal, Manipur, India) \\ ${ }^{2}$ (Consultant General \& Minimal Access Surgeon, Shija Hospitals \& Research Institute, Imphal,Manipur, India)
}

\begin{abstract}
Introduction: Foreign body in tracheobronchial tree is a potentially life threatening situation and it requires emergency removal.

Materials \& Methods: We conducted a retrospective, descriptive study of the patients in which we performed flexible bronchoscopy with suspicion of tracheobronchial foreign bodies from $1^{\text {st }}$ October, 2012 to $30^{\text {th }}$ September, 2014 (2 Years).

Results: Out of 56 suspected cases, tracheobronchial foreign bodies were found in 42 occasions (75\%). Among these 42 cases, most were male (69\%) and common age group was below 5 years (53\%). Most of the patients presented with choking (40\%) while few were asymptomatic (12\%). Most common complication due to delayed removal of foreign body was pneumonia. X-ray was suggestive of foreign body only in 6 cases (14\%). Most common location of foreign body was in right bronchial tree (52\%). Seeds were most common foreign bodies $(38 \%)$.

Conclusion: Diagnosis of tracheobronchial foreign bodies is challenging as few patients can be asymptomatic and plain X-ray fails to detect foreign bodies in majority of cases. Considering the risks associated with tracheobroncheal foreign bodies, it is advisable to perform diagnostic bronchoscopy in all suspected cases.
\end{abstract}

Keywords: Flexible bronchoscopy, Foreign body, Tracheobronchial tree

\section{Introduction}

Foreign body in tracheobronchial tree is a potentially life threatening situation and it requires emergency removal. It is one of the common causes of sudden death in children under 6 years of age. ${ }^{\mathbf{~}}$ The diagnosis is often missed initially, especially in children where the history may be vague and the patient cannot verbalize the events. $^{2}$ In as many as $30 \%$ of patients, symptoms are treated as those of other common diseases, especially in patients with minimal symptoms. ${ }^{\mathbf{3} 4}$ A high index of suspicion is required to make the diagnosis, especially in children and patients who are debilitated. ${ }^{5}$ Extraction by bronchoscopy is the treatment of choice for tracheobronchial foreign bodies. ${ }^{\mathbf{6 , 7 , 9}}$ In the present study, we reviewed our experience of diagnosing \& treating such cases in last 2 years.

\section{Materials \& Methods}

We conducted a retrospective, descriptive study of the patients in which we performed flexible bronchoscopy with suspicion of tracheobronchial foreign bodies from $1^{\text {st }}$ October, 2012 to $30^{\text {th }}$ September, 2014 (2 Years). Approval for the study was taken from the Institutional Ethical Committee and Scientific Committee. We reviewed bronchoscopy register, operation notes and discharge certificates of all the patients and contacted patients when ever needed.

\section{Results}

Out of 56 suspected cases, tracheobronchial foreign bodies were found in 42 occasions (75\%). Among these 42 cases, most were male (Table 1) with male (69\%) to female (31\%) ratio of 2.2/1. Most common age group was below 5 years $(53 \%)$ (Table 2).

\begin{tabular}{|c|c|c|}
\hline $\begin{array}{c}\text { Table 1: Sex of the } \\
\text { patients }(\mathbf{n}=\mathbf{4 2})\end{array}$ & & \\
\hline Sex & Number & $\%$ \\
\hline Male & 29 & $\mathbf{6 9}$ \\
\hline Female & $\mathbf{1 3}$ & $\mathbf{3 1}$ \\
\hline
\end{tabular}

\begin{tabular}{|c|c|c|}
\hline $\begin{array}{c}\text { Table 2: Age of the } \\
\text { patients (n=42) }\end{array}$ & & \\
\hline Age (Years) & Number & $\mathbf{\%}$ \\
\hline$<5$ & $\mathbf{2 2}$ & $\mathbf{5 3}$ \\
\hline $5-15$ & $\mathbf{1 4}$ & $\mathbf{3 3}$ \\
\hline$>15$ & $\mathbf{6}$ & $\mathbf{1 4}$ \\
\hline
\end{tabular}


The commonest symptom was choking (40\%) followed by cough $(24 \%)$ and stridor $(17 \%) .12 \%$ patients were asymptomatic (Table 3). Clinical examination was normal in majority of cases (48\%). Wheeze and decreased air entry noted in $28 \%$ and $24 \%$ of cases respectively (Table 4 ).

\begin{tabular}{|c|c|c|}
\hline $\begin{array}{c}\text { Table 3: Symptoms of the } \\
\text { patients }(\mathbf{n}=\mathbf{4 2})\end{array}$ & & \\
\hline Symptoms & Number & \% \\
\hline Choking & $\mathbf{1 7}$ & $\mathbf{4 0}$ \\
\hline Cough & $\mathbf{1 0}$ & $\mathbf{2 4}$ \\
\hline Stridor & $\mathbf{7}$ & $\mathbf{1 7}$ \\
\hline Asymptomatic & $\mathbf{5}$ & $\mathbf{1 2}$ \\
\hline Haemoptysis & $\mathbf{3}$ & $\mathbf{7}$ \\
\hline
\end{tabular}

\begin{tabular}{|c|c|c|}
\hline $\begin{array}{c}\text { Table 4: Signs of the patients } \\
(\mathbf{n}=\mathbf{4 2})\end{array}$ & & \\
\hline Signs & Number & $\mathbf{\%}$ \\
\hline No sign & $\mathbf{2 0}$ & $\mathbf{4 8}$ \\
\hline Wheeze & $\mathbf{1 2}$ & $\mathbf{2 8}$ \\
\hline Decreased air entry & $\mathbf{1 0}$ & $\mathbf{2 4}$ \\
\hline
\end{tabular}

X-ray was suggestive of foreign body only in 6 cases (14\%). Most commonly removed foreign bodies were seeds (Table 5). Most common location of foreign body was in right bronchial tree (52\%) followed by left bronchial tree (29\%) and trachea (19\%). After removal of foreign bodies, bronchoscopic examination of underlying mucosa was normal in $62 \%$ cases, but granulation and scarring noted in $33 \%$ and $5 \%$ cases respectively. All the foreign bodies were removed successfully by using flexible bronchoscopy. Most commonly used removal tool was three-teethed forcep (in 33\% cases). Combination of different tools used in $11 \%$ of cases (Table 6).

\begin{tabular}{|c|c|c|}
\hline $\begin{array}{c}\text { Table 5: Types of foreign body } \\
(\mathbf{n = 4 2 )}\end{array}$ & & \\
\hline Type & Number & $\mathbf{\%}$ \\
\hline Seeds & $\mathbf{1 6}$ & $\mathbf{3 8}$ \\
\hline Peanut & $\mathbf{9}$ & $\mathbf{2 1}$ \\
\hline Bone & $\mathbf{6}$ & $\mathbf{1 4}$ \\
\hline Button & $\mathbf{4}$ & $\mathbf{1 0}$ \\
\hline Plastic object & $\mathbf{3}$ & $\mathbf{7}$ \\
\hline Metallic fragment & $\mathbf{2}$ & $\mathbf{5}$ \\
\hline Chocolate piece & $\mathbf{2}$ & $\mathbf{5}$ \\
\hline
\end{tabular}

\begin{tabular}{|c|c|c|}
\hline Table 6: Removal tools $(\mathbf{n = 4 2})$ & & \\
\hline Tool & Number & $\mathbf{\%}$ \\
\hline Three-teethed forcep & $\mathbf{1 4}$ & $\mathbf{3 3}$ \\
\hline Alligator forcep & $\mathbf{9}$ & $\mathbf{2 2}$ \\
\hline Wire basket & $\mathbf{7}$ & $\mathbf{1 7}$ \\
\hline Biopsy forcep & $\mathbf{4}$ & $\mathbf{1 0}$ \\
\hline Ureteric forcep & $\mathbf{3}$ & $\mathbf{7}$ \\
\hline $\begin{array}{c}\text { Combinations of above mentioned } \\
\text { tools }\end{array}$ & $\mathbf{5}$ & $\mathbf{1 1}$ \\
\hline
\end{tabular}

Complications due to delayed removal noted in 12 cases and most common complication was pneumonia $(67 \%)$ followed by atelectasis $(25 \%)$ and abscess $(8 \%)$. In all cases, general anaesthesia was given. Average procedure time was 20 minutes. Most patients $(75 \%)$ were discharged on next day. No procedure related complication was noted.

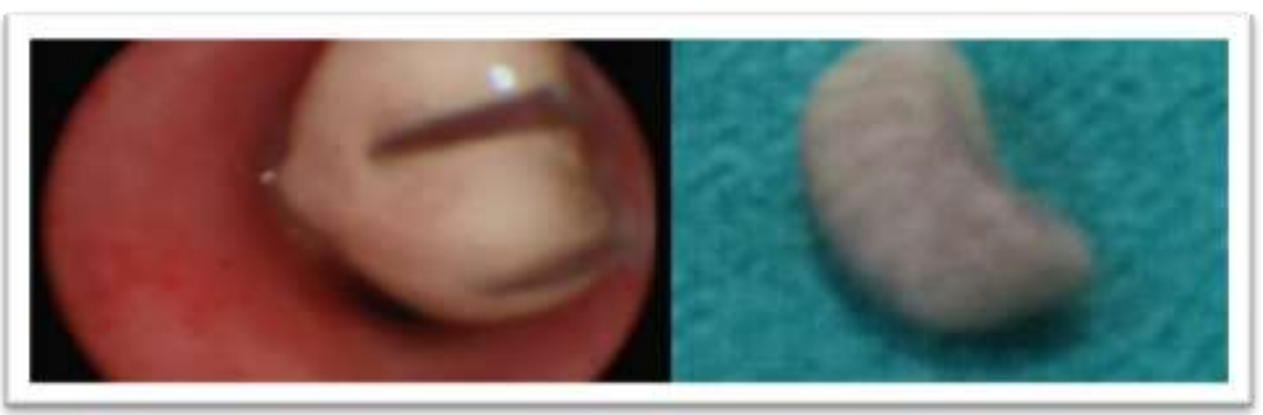

Figure 1: Removal of foreign body from right bronchial tree.

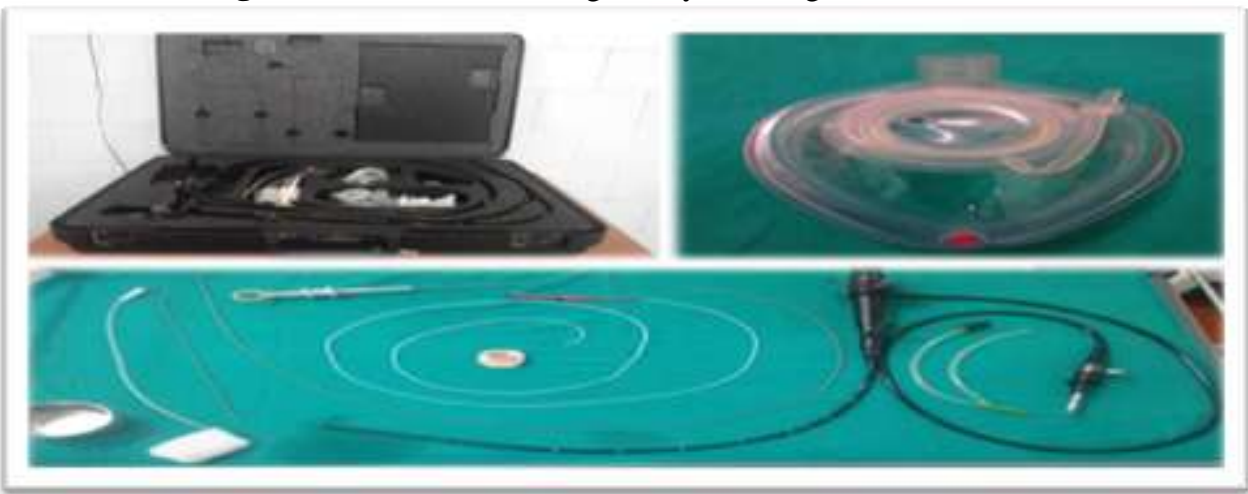

Figure 2: Instruments for flexible bronchoscopy and foreign body removal. 


\section{Discussion}

From our experience, tracheobronchial foreign body cases are less common and similar studies in other centres also experienced so. ${ }^{10,11}$ Male/female ratio in our study is $2.2 / 1$ which is similar to other studies. ${ }^{5,10,12}$ Most of the patients were under 5 years of age and most common symptom was choking. A witnessed choking event is the most important historical information to make an early diagnosis of foreign body aspiration. ${ }^{3}$ Clinical examination is often normal in majority of cases. ${ }^{13}$ Foreign Body aspiration may be occult and remain undiagnosed for years. ${ }^{14} \mathrm{~A}$ high index of suspicion is therefore necessary, especially if there are predisposing factors like neurological deficits, sedative or alcohol use. ${ }^{15}$

Most of the foreign bodies were located in right bronchial tree (52\%) which is similar to other studies. ${ }^{\mathbf{1 0} 16}$ This is because proximal right main bronchus is consistently steeper and slightly wider than the left. ${ }^{17}$ In our study most common foreign bodies were seeds which is similar to other study done by Madkour A et al. ${ }^{18}$ while others found bone ${ }^{10}$, head pin ${ }^{13}$ and peanut ${ }^{19}$ to be most common foreign bodies in their respective studies.

Although postero-anterior and lateral chest X-ray are used as an initial screening test, but often it fails to detect it. ${ }^{10,20}$ This is especially true because the majority of tracheal foreign bodies (seeds) are radiolucent. Radiographic signs that may help in the diagnosis of tracheobronchial FB include atelectasis, post-obstructive pneumonia and air trapping. ${ }^{21}$ Computed tomography (CT) is rapidly becoming the imaging study of choice in stable patients with suspected aspiration. ${ }^{22,23,24}$ We advised CT scan of thorax in selected cases.

Extraction by bronchoscopy is the treatment of choice for tracheobronchial foreign bodies. ${ }^{6,7,89} \mathrm{We}$ successfully removed all the foreign bodies by using flexible bronchoscopy. The success rate of the flexible bronchoscope in removing foreign bodies can be as high as $100 \%$ in experienced hands. ${ }^{25}$ To increase its success rate, flexible bronchoscopy use should be coupled with the necessary equipments like special foreign body forceps. ${ }^{26}$ Although rigid bronchoscopy is considered the gold standard for the removal of foreign bodies from the airways, flexible bronchoscopy should be considered as the first-choice method. ${ }^{27}$ Even just localisation of the foreign body during the initial flexible bronchoscopy allows subsequent rigid bronchoscopy to be shorter in duration with fewer complications. ${ }^{25}$ In all of our cases, general anaesthesia was given; but foreign bodies often can be removed with a flexible bronchoscope under local anesthesia. ${ }^{28}$

Bronchoscopy, performed for tracheobronchial foreign body aspiration, carries a potential life-threatening risk during and after the process. ${ }^{29}$ Though no procedure related complication was noted in our study, several complications like laryngeal edema, bronchospasm, tracheobronchial system bleeding and even death can occur because of the procedure ${ }^{29,30}$ Close communication between the anesthesiologist, bronchoscopist, and assistants is essential. ${ }^{31}$ While removing an object located in the main bronchia, it is possible for it to cause obstruction if it falls in the trachea. Objects that are too big to be taken out with the bronchoscope should be firmly grasped with forceps, when being taken out by bronchoscopy. When the size of the object is larger than the laryngeal gap, which can happen when the object is grasped on one side with the forceps and turned, the object can be grasped right in the middle. If this is not possible, it should be grasped simultaneously with two forceps on both sides. ${ }^{29}$

Delayed removal of foreign body can cause several complications like unresolving pneumonia, lung abscess, recurrent haemoptysis, lung fibrosis, obstructive emphysema and bronchiectasis. ${ }^{10,32}$ It is essential to consider FBA in the differential diagnosis of the above pathologies as removal of the foreign body by a flexible bronchoscope may provide a complete resolution without necessitating a more invasive procedure. ${ }^{33,34}$

The clinician needs to be aware of these risks, take proper precautions, and perform bronchoscopy by taking the medical condition of the patient and characteristics of the inspired foreign body into consideration. ${ }^{29}$ Education aimed at increasing diagnostic acumen of the physicians and heightening of public awareness are the most important steps needed to reduce the morbidity and mortality. ${ }^{19}$

\section{Conclusion}

Diagnosis of tracheobronchial foreign bodies is challenging as few patients can be asymptomatic and plain X-ray fails to detect foreign bodies in majority of cases. Considering the risks associated with tracheobroncheal foreign bodies, it is advisable to perform diagnostic bronchoscopy in all suspected cases. A good coordination between anaesthetists and surgeons is needed to successfully complete this technically challenging procedure.

\section{Acknowledgement}

Thanks to department of General Surgery, Shija Hospitals \& Research Institute, Imphal, Manipur. 


\section{References}

[1]. Ross A H M , Mc Cormack R J M. Foreign body inhalation. J Royal College Surg Edin 1980;75:104-9.

[2]. Sersar SI, Rizk WH, Bilal M, El Diasty MM, Eltantawy TA, Abdelhakam BB, et al. Inhaled foreign bodies: presentation, management and value of history and plain chest radiography in delayed presentation. Otolaryngol Head Neck Surg 2006;134(1):92-9.

[3]. Chiu CY, Wong KS, Lai SH. Factors predicting early diagnosis of foreign body aspiration in children. Pediatr Emerg Care 2005;21(3):161-4.

[4]. Saquib Mallick M, Rauf Khan A, Al-Bassam A. Late presentation of tracheobronchial foreign body aspiration in children. J Trop Pediatr 2005;51(3):145-8.

[5]. Cataneo AJ, Cataneo DC, Ruiz RL Jr. Management of tracheobronchial foreign body in children. Pediatr Surg Int 2008;24(2):1516.

[6]. Gang W, Zhengxia P, Hongbo L, Yonggang L, Jiangtao D, Shengde W. Diagnosis and treatment of tracheobronchial foreign bodies in 1024 children. J Pediatr Surg. 2012;47(11):2004-10.

[7]. Digoy GP. Diagnosis and management of upper aerodigestive tract foreign bodies. Otolaryngol Clin North Am. 2008;41(3):485-96.

[8]. Ciftci AO, Bingol-Kologlu M, Senocak ME, et al. Bronchoscopy for evaluation of foreign body aspiration in children. J Pediatr Surg. 2003;38(8):1170-6

[9]. Divisi D, Di Tommaso S, Garramone M, Di Francescantonio W, Crisci RM, Costa AM, et al. Foreign bodies aspirated in children: role of bronchoscopy. Thorac Cardiovasc Surg. 2007;55(4):249-52.

[10]. Debeljak A, Sorli J, Music E, Kecelj P. Bronchoscopic removal of foreign bodies in adults: experience with 62 patients from $1974-$ 1998. Eur Respir J 1999 Oct;14(4):792-5.

[11]. Limper AH, Prakash UBS. Tracheobronchial foreign bod-ies in adults. Ann Intern Med 1990;112:604-9.

[12]. Mise K, Jurcev Savicevic A, Pavlov N, Jankovic S. Removal of tracheobronchialforeign bodies in adults using flexible bronchoscopy: experience1995-2006. Surg Endosc 2009;23:1360-1364.

[13]. Ahmed Y. S. G., Mohamed S. H. Removal of tracheobronchial foreign bodies using flexible and rigid bronchoscopy. Egyptian Journal of Chest Diseases and Tuberculosis 2012; 61(4):501-504.

[14]. Wolkove W, Kreisman H, Cohen C, Frank H. Occult foreign-body aspiration in adults. JAMA 1982; 248:1350-2

[15]. C M Loo, A A L Hsu, P Eng, Y Y Ong. Case Series of Bronchoscopic Removal of Tracheobronchial Foreign Body in Six Adults. Ann Acad Med Singapore 1998; 27:849-53.

[16]. Zhijun C, Fugao Z, Niankai Z, Jingjing C. Therapeutic experience from 1428 patients with pediatric tracheobronchial foreign body. J Pediatr Surg 2008 Apr;43(4):718-21.

[17]. Tahir N1, Ramsden WH, Stringer MD. Tracheobronchial anatomy and the distribution of inhaled foreign bodies in children. Eur J Pediatr 2009;168(3):289-95.

[18]. Madkour A, Elmansoury A, Sharkawy S. The efficacy of fiberoptic bronchoscopy through laryngeal mask airway in pediatric foreign body extraction. Egypt J Bronchol 2014;8:57-63.

[19]. Tang FL, Chen MZ, Du ZL, Zou CC, Zhao Y. Fibrobronchoscopy treatment of foreign body aspiration in children: an experience of 5 years in Hangzhou City, China. J Pediatr Surg 2006;41:1-5.

[20]. Martinot A, Closset M, Marquette $\mathrm{CH}$, et al. Indicationsfor flexible versus rigid bronchoscopy in children withsuspected foreign body aspiration. Am J Respir Crit CareMed 1997;155:1676-79.

[21]. Whitlock W L, Brown C R, Young M B. Tracheobronchial foreign bodies. Ann Intern Med 1990; $113: 482$

[22]. Haliloglu M, Ciftci AO, Oto A, et al. CT virtual bronchoscopy in the evaluation of children with suspected foreign body aspiration. Eur J Radiol. Nov 2003;48(2):188-92.

[23]. Huang HJ, Fang HY, Chen HC, Wu CY, Cheng CY, Chang CL. Three-dimensional computed tomography for detection of tracheobronchial foreign body aspiration in children. Pediatr Surg Int. Feb 2008;24(2):157-60.

[24]. Bai W, Zhou X, Gao X, Shao C, Califano JA, Ha PK. Value of chest CT in the diagnosis and management of tracheobronchial foreign bodies. Pediatr Int. Aug 2011;53(4):515-8.

[25]. Dikensoy O, Usalan C, Filiz A. Foreign body aspiration: clinical utility of flexible bronchoscopy. Postgrad Mel J 2002;78:399-403.

[26]. Taha, A. The use of fiberoptic bronchoscope to remove aspirated tracheobronchial foreign bodies: Our experience. CRCM 2013; 2(5):285-290.

[27]. Rodrigues AJ1, Oliveira EQ, Scordamaglio PR, Gregório MG, Jacomelli M, Figueiredo VR. Flexible bronchoscopy as the firstchoice method of removing foreign bodies from the airways of adults. J Bras Pneumol 2012;38(3):315-20.

[28]. Swanson KL1, Edell ES. Tracheobronchial foreign bodies. Chest Surg Clin N Am 2001;11(4):861-72.

[29]. Hasdiraz L, Oguzkaya F, Bilgin M, Bicer C.Complications of bronchoscopy for foreign body removal: experience in 1,035 cases. Ann Saudi Med 2006;26(4):283-7.

[30]. Sivakumar A M, Palaksappa K R, Ashok S Naik, Prashant K B, Yogesh B S. Preferred anaesthetic technique for tracheobronchial foreign body-A otolaryngologist'sperspective. Indian J.Anaest 2004;48(2):145-147.

[31]. Fidkowski CW, Zheng H, Firth PG. The Anesthetic Considerations of Tracheobronchial Foreign Bodies in Children: A Literature Review of 12,979 Cases. Anesth Analg 2010;111(4):1016-25.

[32]. Maayan C, Avital A, Elpeleg ON, et al. Complications following oat head aspiration. Pediatr Pulmonol 1993;15:52-4.

[33]. Pogorzelski A, Zebrak J. Scar changes in the bronchus caused by a foreign body. Wiad Lek 1995;48:140-2.

[34]. Mansour Y, Beck R, Danino J, et al. Resolution of severe bronchiectasis after removal of long-standing retained foreign body. Pediatr Pulmonol 1998;25:130-2. 